\title{
Age at breast feeding start and postneonatal growth and survival
}

\author{
Geir Gunnlaugsson, Maria Clotilde da Silva, Lars Smedman
}

\begin{abstract}
Colostrum has important anti-infective properties. It may also somehow promote the development of the child's immunological system. Discarding colostrum, as practised in some cultures, could thus have adverse health consequences beyond the neonatal period. To test this hypothesis, the age at breast feeding start of 734 healthy newborns in urban GuineaBissau was ascertained. The children were then prospectively followed up to 3 years of age. Eighty nine deaths occurred during the study. The probability of death in the age interval 28 days to 3 years was about $20 \%$. The child's age at breast feeding start had no statistical impact on postneonatal growth or survival. As a single measure, early breast feeding start is not likely to make much difference for the long term growth or survival of children living under material poverty conditions.
\end{abstract}

(Arch Dis Child 1993; 69: 134-137)

Colostrum is excreted in small amounts during the first few days after delivery and has distinctive characteristics that suggest a special role for this early milk in protecting the newborn child from infections. The concentrations of secretory IgA and IgM are higher than in the mature milk.' Through the enteromammary and bronchomammary axes these antibodies are specific for antigens in the environment the mother and her baby share. ${ }^{23}$ The concentration of immunocompetent cells is also high, about $10 \%$ being $T$ lymphocytes. ${ }^{4}$ Further, colostrum has a high content of vitamin A. ${ }^{5}$ In clinical practice, receiving early breast milk has been shown to prevent subsequent bacterial infections in newborn babies. ${ }^{67}$

In many parts of the world, colostrum is discarded by mothers because of ideas about it being worthless or dangerous for the child. ${ }^{8}$ Studies from Guatemala, Costa Rica, and Pakistan indicate that such practices may have health consequences beyond the neonatal period..$^{9-11}$ It is possible that the first milk somehow triggers the development of the child's immune system, for example through ingested maternal immunocompetent cells, and that consequences are critical in Third World environments where infections abound.

With this hypothesis in mind, we studied breast feeding start in Guinea-Bissau, where colostrum taboos exist, ${ }^{12}$ and found it to be relatively late in the largest ethnic group (Balanta) in a periurban sample. ${ }^{13}$ We have now analysed the three year follow up on the same children to find out if the age at breast feeding start influenced their growth or survival after the neonatal period in the microbiologically aggressive setting concerned.

\section{Subjects and methods}

Guinea-Bissau is situated about $12^{\circ}$ north on the west coast of Africa south of Senegal. The single rainy season lasts from June to October. Falciparum malaria is mesoendemic, with little chloroquine resistance being found as yet in the time period concerned. The capital Bissau is growing rapidly and had a population of about 120000 at the time of the study. The follow up of children took place in the periurban settlement area Bandim 1. Its population of 8000 is ethnically mixed with Papel dominating, but the country's largest group, the Balanta, is also well represented. The houses with verandahs have earth or rough concrete floors and each household of 5-15 persons has but one or two rooms. There are simple latrines and badly protected pit wells. Few houses have piped water. Breast feeding is practised by most mothers well beyond the child's second birthday, ${ }^{14}$ and formula feeding virtually does not exist.

\section{STUDY GROUP}

Since 1978 pregnant women, births, and deaths have been registered in Bandim. ${ }^{15}$ After birth, mothers are visited at home by a health worker and the infant weighed naked or the birth weight registered according to hospital records. During the period January 1984 to April 1986 a brief questionnaire was attached to this ongoing registration of births. The day and hour when the child was first given the breast was asked, along with the mother's age, parity, education, ethnic group, and attendance at antenatal clinics as well as the place of birth, sex of child, and the use of supplements, as described in detail elsewhere..$^{13}$ Because the study of breast feeding start was designed to assess the effect of cultural beliefs on behaviour, sick or otherwise weak children were excluded. The original study cohort thus consisted of 734 full term, vaginally delivered, singleton newborns without signs of disease. Half of the mothers were interviewed before three days, $91 \%$ before two weeks, and all within 28 days after giving birth. Children who had left the study before that age were excluded (nine died, eight moved), leaving 717 to enter the follow up at 28 days of age. Ten children could not be classified with regard to age at breast feeding start (before or after 24 hours). The use of prelacteal and supplemental feeds was widespread in the study area, and $84 \%$ of the children had received sugared water at interview.

The follow up status of the children was determined at general outdoor examinations

\footnotetext{
Dr Geir Gunnlaugsson, Department of Paediatrics, St Göran's Children's Hospital,

Accepted 2 March 1993

Centre of Maternal and Guinea Bissau Department of Children's Hospital Stockholm, Swede Geir Gunnlaugs Lars Smedman
} 
Table 1 Follow up of 717 healthy newborn children from 28 days of age

\begin{tabular}{llcll}
\hline $\begin{array}{l}\text { Start of age } \\
\text { interval } \\
\text { (months) }\end{array}$ & $\begin{array}{l}\text { No of } \\
\text { children } \\
\text { entering } \\
\text { interval }\end{array}$ & $\begin{array}{l}\text { No of } \\
\text { deaths }\end{array}$ & $\begin{array}{l}\text { No } \\
\text { leaving } \\
\text { follow up }\end{array}$ & $\begin{array}{l}\text { \% } \\
\text { Weighed }\end{array}$ \\
\hline 28 days & 717 & 5 & 26 & 51 \\
3 & 686 & 18 & 16 & 63 \\
6 & 652 & 14 & 23 & 66 \\
9 & 615 & 7 & 18 & 68 \\
12 & 590 & 7 & 75 & 70 \\
15 & 508 & 8 & 77 & 66 \\
18 & 423 & 4 & 47 & 66 \\
21 & 372 & 7 & 59 & 65 \\
24 & 306 & 7 & 99 & 69 \\
27 & 200 & 6 & 57 & 65 \\
30 & 137 & 4 & 49 & 75 \\
33 & 84 & 1 & 30 & 58 \\
36 & 53 & 1 & 39 & 78 \\
39 & 13 & 0 & 13 & 62 \\
$1-39$ & 717 & 89 & & \\
\hline
\end{tabular}

*Calculated as number of children weighed/(number entering age interval -0.5 [number of deaths + number moved out]).

every three months in eight well defined zones, classifying each as re-examined, temporarily absent, dead, or permanently moved out of the studied community. If necessary, status of absentees was established by means of a home visit. Due to the health intervention programme, about two thirds of the children were vaccinated with BCG, three quarters against diphtheria, tetanus, pertussis (DTP), and polio, either partially or fully, and four fifths against measles. For children who had died from disease, an adult family member was asked about the symptoms preceding death. Deaths were assigned to a causative category on the basis of the lay registration of symptoms and the child's age. This classification was done independently by two paediatricians (GG, LS) with few discrepancies.

Table 1 shows the children's fate during the study period and the proportion of an estimated mid-interval number of children who were weighed in each age interval. The main reason for absence at the weighing sessions was the travelling pattern of the women with their children, which is a cultural feature. If not leaving the study because of death or moving, the cohort children contributed follow up time of one to three years.

\section{STATISTICAL ANALYSIS}

The CDC Anthropometric Software Package (version 3.0) was used for transforming the weights to SD scores of weight for age. The Cox

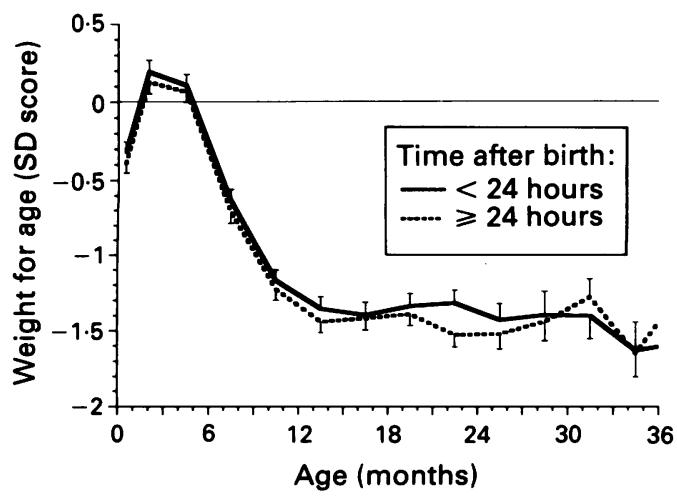

Figure 1 Mean SD score of weight for age by age and timing of breast feeding start. multivariate regression technique was applied in the form of the PHREG procedure in the Statistical Analysis System (SAS). ${ }^{16}$ When only the month or the interexamination period of death or moving were known, the 15th of that month or the middle of the period were used as approximations. $\log (-\log )$ curves of survival were computed for the independent variables included in the multivariate analysis in order to test the proportionality assumption which was found valid. Relative risks were calculated with $95 \%$ confidence intervals $(\mathrm{CI})$, based on the beta coefficient and its SE $(\exp \{$ beta $(1.96) \times \mathrm{SE}\})$. Hence, if a high variable value is connected with better survival (lower hazard), beta will be negative and relative risk less than one. Predictions of survival were calculated using the same software. The 'current life table' calculation technique was also applied ${ }^{17}$ with very similar results with regard to overall mortality.

\section{Results}

GROWTH

Due to the inclusion criteria of the study, 44 children out of the 554 examined in the first week of life weighed below $2500 \mathrm{~g}$. None weighed less than $2000 \mathrm{~g}$. The mean weight (SD) was 3100 (500) g. There was no difference between the children who were given the breast before or after 24 hours of age.

Figure 1 depicts the postneonatal growth as mean SD score of weight for age up to 3 years of age. The bars represent SEM for early and late starters plotted in the middle of the age interval concerned. These bars overlap and no statistically significant difference existed between the two groups. Above 1 year of age, the mean value of weight for age SD score is about $-1 \cdot 4$. No significant statistical impact could be discerned for the other variables under study (see table 2), including season of the year.

\section{SURVIVAL}

Table 2 gives the coding, the variable values, and their frequencies for the independent variables and attributes along with their bivariate statistical effect on postneonatal survival. Age at breast feeding start had no statistical effect on survival. On the other hand, attendance at antenatal clinics had a significant impact with a relative risk of $0.61(95 \% \mathrm{CI} 0.38$ to 0.99$)$. The education of the mother showed a tendency (relative risk 0.73 and $95 \%$ CI 0.53 to 1.02 ) towards more education being connected with lower hazard, that is, better survival. The variables parity and maternal age, which could be suspected of having a non-linear relationship with mortality hazard, were tested as indicator $(0,1)$ variables for each one of their values, but without significant results. No combination of the independent variables gave a statistically significant explanatory model.

Figure 2 is a prediction based on the observed mortality. The curves represent postneonatal survival for children who were and who were not given the breast within 24 hours of birth. Maternal education, age, attendance at antenatal clinics, ethnic background, and the child's sex 
Table 2 Frequencies and statistical impact of the explanatory variables on postneonatal survival of 717 children up to 3 years of age by Cox regression

\begin{tabular}{|c|c|c|c|c|}
\hline Independent variable & Value & $\mathrm{No}(\%)$ & $\begin{array}{l}\text { Deaths } / 100 \\
\text { child years } \\
\text { followed }\end{array}$ & $\begin{array}{l}\text { Relative risk } \\
(95 \% \mathrm{CI})\end{array}$ \\
\hline \multicolumn{4}{|l|}{ Ethnic background: } & \multirow[t]{2}{*}{$0.81(0.45$ to 1.46$)$} \\
\hline $\begin{array}{l}\text { Balanta } \\
\text { Other }\end{array}$ & $\begin{array}{l}1 \\
0\end{array}$ & $\begin{array}{l}113(16) \\
604(84)\end{array}$ & $\begin{array}{l}6 \cdot 13 \\
7 \cdot 35\end{array}$ & \\
\hline \multicolumn{4}{|l|}{ Age of mother (years): } & \multirow[t]{2}{*}{$0.98(0.70$ to 1.38$)$} \\
\hline $\begin{array}{l}<20 \\
20-29 \\
\geq 30\end{array}$ & $\begin{array}{l}1 \\
2 \\
3\end{array}$ & $\begin{array}{l}128(18) \\
423(62) \\
135(20)\end{array}$ & $\begin{array}{l}6 \cdot 40 \\
7 \cdot 62 \\
6 \cdot 57\end{array}$ & \\
\hline \multicolumn{4}{|l|}{ Parity: } & \multirow[t]{2}{*}{$1.08(0.79$ to 1.48$)$} \\
\hline $\begin{array}{l}1 \\
2-4\end{array}$ & $\begin{array}{l}1 \\
2 \\
3\end{array}$ & $\begin{array}{r}98(14) \\
376(52) \\
241(34)\end{array}$ & $\begin{array}{l}6 \cdot 23 \\
7 \cdot 19 \\
7 \cdot 49\end{array}$ & \\
\hline \multicolumn{4}{|l|}{ Education (years): } & \multirow[t]{2}{*}{$0.73(0.53$ to 1.02$)$} \\
\hline $\begin{array}{l}\text { None } \\
1-4 \\
\geq 5\end{array}$ & $\begin{array}{l}1 \\
2 \\
3\end{array}$ & $\begin{array}{l}440(62) \\
165(23) \\
103(15)\end{array}$ & $\begin{array}{l}7 \cdot 99 \\
6 \cdot 86 \\
3 \cdot 59\end{array}$ & \\
\hline \multicolumn{4}{|l|}{ Attendance at antenatal clinic: } & \multirow[t]{2}{*}{$0.61(0.38$ to 0.99$)$} \\
\hline $\begin{array}{l}\text { No } \\
\text { Yes }\end{array}$ & $\begin{array}{l}0 \\
1\end{array}$ & $\begin{array}{l}123(17) \\
585(83)\end{array}$ & $\begin{array}{r}10 \cdot 53 \\
6.45\end{array}$ & \\
\hline \multicolumn{4}{|l|}{ Place of birth: } & \multirow{2}{*}{$0.80(0.51$ to 1.25$)$} \\
\hline $\begin{array}{l}\text { Home } \\
\text { Hospital }\end{array}$ & $\begin{array}{l}1 \\
2\end{array}$ & $\begin{array}{l}444(62) \\
269(38)\end{array}$ & $\begin{array}{l}7 \cdot 67 \\
6 \cdot 10\end{array}$ & \\
\hline \multicolumn{4}{|l|}{ Sex: } & \multirow[t]{2}{*}{$0.82(0.54$ to 1.25$)$} \\
\hline $\begin{array}{l}\text { Male } \\
\text { Female }\end{array}$ & $\begin{array}{l}1 \\
2\end{array}$ & $\begin{array}{l}365(51) \\
352(49)\end{array}$ & $\begin{array}{l}7 \cdot 82 \\
6 \cdot 46\end{array}$ & \\
\hline & \multirow[t]{3}{*}{$0.90(0.59$ to 1.37$)$} \\
\hline $\begin{array}{l}<24 \\
\geq 24\end{array}$ & $\begin{array}{l}0 \\
1\end{array}$ & $\begin{array}{l}345(49) \\
362(51)\end{array}$ & $\begin{array}{l}7 \cdot 37 \\
6 \cdot 67\end{array}$ & \\
\hline $\begin{array}{l}>36 \\
>60 \\
\geq 84\end{array}$ & & $\begin{array}{r}174 \\
59 \\
17\end{array}$ & $\begin{array}{l}7 \cdot 73 \\
7 \cdot 70 \\
6 \cdot 91\end{array}$ & \\
\hline $\begin{array}{l}\text { Weight first week } \\
\text { (SD-score) }\end{array}$ & continuous & $554(77)$ & & $0.93(0.74$ to 1.15$)$ \\
\hline $\begin{array}{l}2000-2499 \mathrm{~g} \\
2500-2999 \mathrm{~g} \\
3000-3999 \mathrm{~g} \\
\geq 4000 \mathrm{~g}\end{array}$ & & $\begin{array}{r}44 \\
141 \\
331 \\
38\end{array}$ & $\begin{array}{l}8 \cdot 64 \\
8 \cdot 32 \\
6 \cdot 65 \\
6 \cdot 62\end{array}$ & \\
\hline
\end{tabular}

and weight for age (SD score) in the first month of life are taken statistically into account. No difference is discernible between these groups in terms of survival. Out of 1000 children aged 28 days, the overall estimated number of survivors at three years would be 785 (95\% CI 774 to 798 ).

The 89 deaths that occurred in the course of follow up were assigned to causative categories as shown in table 3. Acute respiratory infection stands out as the leading definable cause of death. Breast feeding status was known for $46 / 89$ dead children (52\%). Four out of 32 children were weaned at death before 18 months of age and this was the case for $9 / 14$ who died at older ages. Of the 89 dead children, $32(36 \%)$ had been immunised with BCG, 47 (53\%) with measles, and $28(30 \%)$ partially and $36(40 \%)$ fully with DTP and polio vaccine.

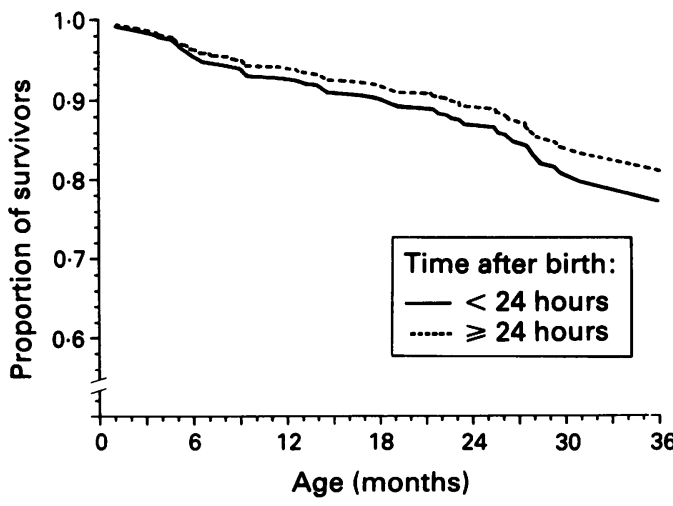

Figure 2 Estimated proportion of survivors by age and timing of breast feeding start. Cox regression as PHREG in SAS. Mother's age, education, antenatal clinic attendance and ethnic background, child's sex, and SD score of weight for age in the neonatal period were set to their mean values.

\section{Discussion}

A periurban community sample of 717 children was followed up prospectively up to three years with 89 recorded deaths. The children were healthy at birth without known perinatal risk factors and entered the study at 28 days of age. Their age at breast feeding start, ascertained soon after birth, had no statistical impact on their growth or survival, whereas the mother's attendance at antenatal clinics was significantly associated with better survival. There was also a tendency for maternal education to have a positive impact. The presence of these expected associations strengthens the conclusion that the child's age at breast feeding start had no important effect on the observed mortality. However, not many mothers waited long before giving the breast (table 2) and almost all children probably received some colostrum. Even if the immunoglobulin and cell contents decrease quickly in the first few days in terms of concentration, the total amount of milk increases and even the children with delayed breast feeding start may have ingested enough maternal lymphocytes to trigger the development of their immune systems. Thus in communities where colostrum taboos exist, such as in Guinea-Bissau, ${ }^{12}{ }^{13}$ it is not certain that the delay of breast feeding start is sufficient for it to have any long term impact on child health. However, apart from the hypothesised long term effect there are several other reasons why the newborn should be given the breast immediately after birth, as recommended in the 'babyfriendly hospital initiative' of the World Health Organisation and Unicef. ${ }^{18}$

Some other studies have found improvement in child health in line with the above hypothesis. In Guatemala, early mother-infant contact was associated with increased breast feeding prevalence and fewer infections throughout the first year of life.' In an area of Costa Rica, a dramatic reduction in infant mortality was attributed to promotion of early mother-infant contact and breast feeding. ${ }^{10}$ Recently, delayed initiation of breast feeding of more than 24 hours after birth was identified as a risk factor for acute and persistent diarrhoea among Pakistani boys of 6-36 months of age. ${ }^{11}$ However, none of these studies singled out the child's age at the start of breast feeding as we did. The present study seems to be the only prospective community study on this matter, and in addition, the follow up was blind to the 'case-control' status of the child.

This study did not address the role of colostrum taboos for neonatal mortality. However, a 1979 study registered 21 neonatal deaths in the same community of which 11 occurred in the first 24 hours of life. ${ }^{19}$ The age profile of neonatal mortality has been found equally low in other similar settings. ${ }^{20}$ Where the bulk of neonatal mortality occurs so early, colostrum cannot be expected to have any significant protective role. Instead, improvements in obstetric care stand out as important.

An association between antenatal clinic attendance and survival has been observed in similar settings before. ${ }^{21}$ This may reflect that antenatal care to the mother improves the health of her offspring. In addition, establishing con- 
Table 3 Causative category of postneonatal mortality and mortality rate among 717 children

\begin{tabular}{lc}
\hline Causative category & No of deaths \\
\hline Acute respiratory infections & 30 \\
Fever & 20 \\
Diarrhoea & 13 \\
Other & 9 \\
Unknown & 17 \\
Total & 89 \\
Child months followed (years) & $14285 \cdot 57(1190 \cdot 46)$ \\
Deaths/100 child years followed & $7 \cdot 48$
\end{tabular}

tact with the health centre probably leads to better follow up and more frequent contacts for the young child as well. However, selection effects may also be at work. The minority of pregnant women who did not attend antenatal clinics at the time (table 2 ) were probably an atrisk group with distinct social and personal characteristics. Interestingly, attendance at antenatal clinics was also a significant determinant of early breast feeding start in this group of women. ${ }^{13}$

Child health in the studied community is under the influence of a multitude of negative factors, as evidenced by the poor nutritional state and a $20 \%$ mortality risk. Under these conditions differential age at breast feeding start had no impact on the outcome variables growth and survival. This does not exclude the possibility of an effect on morbidity.

Thanks are due to the Danish medical student team from the International Medical Cooperation Committee working in Bandim under the supervision of Dr Peter Aaby, especially to Bodi Stenvang-Hansen Niels-Christian Helm-Petersen, Thager Gorm Stenvang-Hansen, Niels-Christian Helm-Petersen, Thøger Gorm Jensen, Henrik Hansen, Hans Kristiansen, Jesper Thărup, and Anja Poulsen. The Guinean health workers in Bandim were Angelina da Silva, Fatima Turé, Matarina Có, Carolina Barbosa, Martins, and Candida Nanque, all of whom are gratefully acknowledged for their skill and endurance.

1 Ogra SS, Ogra PL. Immunologic aspects of human colostrum and milk. I. Distribution characteristics and concentration of immunoglobulins at different times after the onset of lactation. F Pediatr 1978; 92: 546-9.
2 Mestecky J, Russell MW, Jackson S, Brown TA. The human IgA system: a reassessment. Clin Immunol Immunopathol

3 Hanson LA, Brandtzaeg P. The mucosal defense system. In: Stiehm ER, ed. Imimunological disorders in infants and children. Philadelphia: Saunders, 1989: 116-55.

4 Richie ER, Steinmetz KD, Meistrich ML, Ramirez I, Hilliard K. T lymphocytes in colostrum and peripheral blood diffe in their capacity to form thermostable E-rosettes. $\mathcal{F}$ Immunol 1980; 125: 2344-6.

5 Gebre-Medhin M, Vahlquist A, Hofvander Y, Uppsäll L, Vahlquist B. Breast milk composition in Ethiopian and Swedish mothers. I. Vitamin A and $\beta$-carotene. Am $\mathcal{F}$ Clin Nutr 1976; 29: 441-51.

6 Winberg J, Wessner G. Does breast milk protect against septicaemia in the newborn? Lancet 1971; i: 1091-4.

7 Ashraf RN, Jalil F, Zaman S, et al. Breast feeding and protection against neonatal sepsis in a high risk population. Arch Dis Child 1991; 66: 488-90.

8 Morse JM, Jehle C, Gamble D. Initiating breast feeding: a world survey of the timing of postpartum breast feeding. Int $\mathcal{F}$ Nurs Stud 1990; 27: 303-13.

9 Sosa R, Kennel JH, Klaus M, Urrutia JJ. The effect of early mother-infant contact on breast feeding, infection and growth. In: Elliott $\mathrm{K}$, Simons DWF, eds. Breast feeding and the mother. Amsterdam: Elsevier North Holland, 1976: 179-93.

10 Mata $L$, Allen MA, Jiménez $P$, et al. Promotion of breast feeding, health, and growth among hospital-born neonates, feeding, health, and growth among hospital-born neonates, and among infants of a rural area of Costa Rica. In: Chen LC, Scrimshaw NS, eds. Diarrhoea and malnutrition. Interactions, mechanism

11 Badruddin SH, Islam A, Hendricks KM, et al. Dietary risk factors associated with acute and persistent diarrhea in children in Karachi, Pakistan. Am $\mathcal{F}$ Clin Nutr 1991; 54 745-9.

12 Gunnlaugsson G, Einarsdóttir J. Colostrum and ideas about bad milk: a case study from Guinea-Bissau. Soc Sci Med 1993; 36: 283-8

13 Gunnlaugsson G, da Silva MC, Smedman L. Determinants of delayed initiation of breast feeding: a community and hospital study from Guinea-Bissau. Int $f$ E pidemiol 1992; 21. hospital

14 Smedman L. The survival and growth of the children: a community study in Guinea-Bissau. Stockholm: Karolinska Institute, 1986. (Doctoral thesis.)

15 Aaby P, Knudsen K, Jensen TG, et al. Measles incidence, vaccine efficacy, and mortality in two urban African areas with high vaccination coverage. $\mathcal{F}$ Infect Dis $1990 ; 162$ : 1043-8.

16 SAS Institute. SAS technical report P-217 SAS/STAT sofrware: the PHREG procedure. Cary, North Carolina: SAS Institute Inc, 1991.

17 SAS Institute, $\mathcal{F M P}$ user's manual. Cary, North Carolina: SAS Institute Inc, 1989.

18 World Health Organisation/Unicef. The baby-friendly hospital initiative: a global effort to give babies the best possible start in initiative: a global effort to give ba

19 Smedman L, Aaby P, Lindeberg A, Zetterström R. Survival $0-6$ years of age in a periurban community in Guinea-Bissau: a longitudinal assessment. Ann Trop Paediatr 1986; 6: 67-72.

20 Puffer RR, Serrano CV. Patterns of mortality in childhood. Report of the inter-American investigation of mortality in childhood. (Scientific Publication No. 262.) Washington, DC: Pan American Health Organization, 1973.

21 Ahmad OB, Eberstein IW, Sly DF. Proximate determinants of child mortality in Liberia. $\mathcal{F}$ Biosoc Sci 1991; 23: 313-26. 